\title{
Viral and bacterial co-infection in pneumonia: do we know enough to improve clinical care?
}

\author{
Kelly A. Cawcutt ${ }^{1}$ and Andre C. Kalil $1^{1,2^{*}}$
}

Keywords: Viral, Bacterial, Pneumonia

Both bacterial and viral pneumonia are well accepted entities; however, with evolving diagnostics there has been increasing interest in the pathogenesis, epidemiology, presentation, and prognosis of viral pneumonias. In addition, the concept of viral and bacterial co-infections in pneumonia is an area of growing research and may be best recognized among patients with influenza who develop secondary bacterial infections; there was particular interest in this after the 2009 pandemic [1-4]. However, in the setting of increasing molecular diagnostics, particularly multiplex PCR platforms, there is an opportunity to better define the epidemiology of co-infections and their impact on clinical diagnosis and patient outcomes $[5,6]$. There is some evidence that dual infection may worsen patient outcome, including severity of disease and mortality $[1,2]$. With this in mind, the article by Voiriot et al. [7], "Viral-bacterial coinfection affects the presentation and alters the prognosis of severe community-acquired pneumonia", adds to our expanding knowledge base in this arena.

Prior studies have focused on community-acquired pneumonia (CAP) with multiplex pathogen panels, and rates of positivity for concurrent viral detection have ranged up to approximately half of patients; however, detecting a virus does not necessarily imply the virus is directly affecting the patient's current clinical illness $[1,3,4,8]$. The study by Voiriot et al. is a single center, retrospective study of critically ill patients admitted to an ICU between October 2011 and June 2015 for community-acquired pneumonia who also had a

\footnotetext{
* Correspondence: akalil@unmc.edu

${ }^{1}$ Department of Internal Medicine, Division of Infectious Diseases, University of Nebraska Medical Center, Omaha, NE, USA

${ }^{2}$ University of Nebraska Medical Center, 985400 Nebraska Medical Center, Omaha, NE 68198, USA
}

(c) The Author(s). 2017 Open Access This article is distributed under the terms of the Creative Commons Attribution 4.0 International License (http://creativecommons.org/licenses/by/4.0/), which permits unrestricted use, distribution, and reproduction in any medium, provided you give appropriate credit to the original author(s) and the source, provide a link to the Creative Commons license, and indicate if changes were made. The Creative Commons Public Domain Dedication waiver (http://creativecommons.org/publicdomain/zero/1.0/) applies to the data made available in this article, unless otherwise stated.

multiplex retrograde pathogen panel completed within $72 \mathrm{~h}$ of admission to the ICU. Patients were categorized based on pathogen, including bacterial, viral, mixed viral and bacterial pathogens, and no etiology based on microbiologic data obtained. The primary endpoint was to identify specific features regarding presentation and prognosis of mixed viral bacterial coinfected patients. Clinical course was evaluated via a composite criterion of "complicated course" including hospital death or utilization of mechanical ventilation for greater than 7 days. The study included 174 patients that were predominantly male and of old age. Patients with microbiologic documentation of infection included 144 patients: $52.3 \%$ had at least one bacterium identified and $56.3 \%$ had at least one virus identified. Of these, 45 had a mixed bacterial and viral pneumonia per the investigators' criteria; 15 were influenza and 14 were picornavirdae. In the analyses, the composite "complicated course" achieved statistical significance, with higher rates in the mixed group. Presentations were also altered, with increased groundglass opacities radiographically and increased severity of illness among those with mixed infection. It is of note, however, that radiographic findings for bacterial and viral pneumonia may have significant overlap and have historically not been particularly predictive of single entity, dual, or mixed infection [1].

This retrospective study has several potential limitations (e.g., selection bias, confounding by indication of ordering or not the multiplex PCR panel) but the results, limited as they may be, demonstrate that over half of patients admitted to an ICU with presumed communityacquired pneumonia have detectable virus at the time of presentation, consistent with other studies noted above. In the study by Voiriot et al., dual infection with mixed 
bacterial and viral pathogens was associated with worsening patient outcomes. Interpretation of the study is somewhat limited as it is difficult to ascertain the clinical relevance of the detection of virus given the underlying knowledge that viral shedding is not uncommon. Viral shedding could be a surrogate marker for disease severity associated with the primary bacterial pneumonia. However, the worsened composite outcome would suggest that, regardless of colonization, shedding, or active infection, the presence of concurrent virus may hold prognostic value. From a clinician standpoint this becomes increasingly of concern as we detect episodes of mixed infection as very few of the viruses detected on multiplex platforms have active treatment options. Further, it can be difficult in particular patients, such as those with underlying pulmonary disease, to ascertain what may be bacterial colonization or shedding versus active viral infection $[6,8]$. The study by Voiriot et al. did not include discussion of prior infections, particularly in patients with an existing immunocompromised state that may have predisposed them to persistent viral shedding, which can last for months.

With all of this in mind, the study by Voiriot et al. reinforces prior literature that CAP may be far more complex than has been historically recognized, with potential dual active infections, possible immune-modulating effects of some viruses, interactions of the pulmonary microbiome, and variations in clinical presentation and prognosis that may be secondary to direct pathogen effect versus host immune response, or the combination of all of the above $[1,8]$. Further prospective studies are needed to better determine the role of these viruses and their interactions in patients with CAP. Unfortunately, at this time the knowledge of dual infection does not guarantee changes in clinical practice that would impact individual patient outcomes given the lack of proven causal effects from viral-bacterial co-infections, as well as the paucity of effective antiviral therapy available. Detecting a single virus as the pathogen would ideally equate to improved antimicrobial stewardship, but the legitimate concern for dual infection may preclude this [5]. However, it is of great importance that recognition of active viral replication may portend clinical value from the infection prevention standpoint as appropriate isolation may prevent nosocomial spread of viral illnesses, particularly given the high rate of virus detection $[5,9]$. Finally, preventative strategies with vaccination for both bacterial and viral pathogens remain of paramount importance.

Abbreviations

CAP: community-acquired pneumonia; PCR: polymerase chain reaction
Funding

None.

Availability of data and materials

Not applicable.

Authors' contributions

Both authors contributed to the manuscript. Both authors read and approved the final manuscript

Authors' information

Not applicable.

Competing interests

The authors declare that they have no competing interests.

Consent for publication

Not applicable.

Ethics approval and consent to participate

Not applicable.

Published online: 26 January 2017

References

1. Ruuskanen $\mathrm{O}$, Lahti $\mathrm{E}$, Jennings LC, Murdoch DR. Viral pneumonia. Lancet. 2011;377(9773):1264-75

2. Martin-Loeches I, J Schultz M, Vincent JL, Alvarez-Lerma F, Bos LD, SoléViolán J, Torres A, Rodriguez A. Intensive Care Med. 2016. PMID:27709265. [Epub ahead of print].

3. Choi S-H, Hong S-B, Ko G-B, Lee Y, Park HJ, Park S-Y, Moon SM, Cho O-H, Park K-H, Chong YP. Viral infection in patients with severe pneumonia requiring intensive care unit admission. Am J Respir Crit Care Med. 2012; 186(4):325-32.

4. Karhu J, Ala-Kokko T, Vuorinen T, Ohtonen P, Syrjälä H. Lower respiratory tract virus findings in mechanically ventilated patients with severe community-acquired pneumonia. Clin Infect Dis. 2014;59(1):62-70.

5. Hanson KE, Couturier MR. Multiplexed molecular diagnostics for respiratory, gastrointestinal, and central nervous system infections. Clin Infect Dis. 2016;63(10):1361-7.

6. Byington CL, Ampofo K, Stockmann C, Adler FR, Herbener A, Miller T, Sheng X, Blaschke AJ, Crisp R, Pavia AT. Community surveillance of respiratory viruses among families in the Utah Better Identification of Germs-Longitudinal Viral Epidemiology (BIG-LoVE) study. Clin Infect Dis. 2015;61(8):1217-24.

7. Voiriot G, Visseaux B, Cohen J, Nguyen LB, Neuville M, Morbieu C, Burdet C, Radjou A, Lescure FX, Smonig R, et al. Viral-bacterial coinfection affects the presentation and alters the prognosis of severe community-acquired pneumonia. Crit Care. 2016;20(1):375

8. Lieberman D, Shimoni A, Shemer-Avni Y, Keren-Naos A, Shtainberg R, Lieberman D. Respiratory viruses in adults with community-acquired pneumonia. CHEST J. 2010;138(4):811-6.

9. Wiemken T, Peyrani P, Bryant K, Kelley R, Summersgill J, Arnold F, Carrico R, McKinney W, Jonsson C, Carrico K. Incidence of respiratory viruses in patients with community-acquired pneumonia admitted to the intensive care unit: results from the Severe Influenza Pneumonia Surveillance (SIPS) project. Eur J Clin Microbiol Infect Dis. 2013;32(5):705-10. 